Risk-seeking or impatient? Disentangling variance and time in hazardous behaviors

Mélusine Boon-Falleur ${ }^{\mathrm{a}, 1}$, Nicolas Baumard ${ }^{\mathrm{a}, 2}$, and Jean-Baptiste Andréa,2

anstitut Jean Nicod, Département d'études cognitives, ENS, EHESS, PSL University, CNRS, 29 rue d'Ulm, 75005 Paris France

${ }^{1}$ Corresponding author: mboonfalleur@clipper.ens.fr

${ }^{2}$ contributed equally 


\begin{abstract}
Individual observations of risky behaviors present a paradox: individuals who take the most risks in terms of hazards (smoking, speeding, risky sexual behaviors) are also less likely to take risks when it comes to innovation, financial risks or entrepreneurship. Existing theories of risk-preferences do not explain these patterns. From a simple model, we argue that many decisions involving risk have a temporal dimension, and that this dimension is often the main determinant of individual choices. In many real life instances, risk taking amounts to damaging the individual's capital (whether embodied capital, financial capital, social reputation, etc.), which would affect her over a long period of time after the risky decision. In evolutionary terms, the marginal cost of this type of risky behavior depends on the relative importance of the future in the individual's fitness (e.g. her time horizon). Because the cost of a degradation of their capital will be paid for an effective shorter period of time, individuals with short time horizons will give less importance to this degradation. This approach explains patterns of behaviors observed across socio-economic groups and put forward new approaches to prevent hazardous behaviors such as smoking.
\end{abstract}

Keywords: Behavioral Ecology | Risk Taking | Time Discounting 


\section{Risk-seeking or impatient? Disentangling variance and time in hazardous behaviors}

\section{Introduction}

Individuals constantly have to make decisions involving risk such as choosing between different investment options, deciding whether to wear a helmet, or selecting a career. These decisions are similar in that their outcomes are not deterministic; instead there is some variance in the possible payoffs. Given the prevalence of situations where payoffs are uncertain in daily life, there has been considerable interest in how humans make decisions involving risk. Empirical evidence has shown that individuals differ in the degree of risk they take. An individual who is more risk seeking will accept more variance to increase the expected value of payoffs, while an individual who is more risk averse will prefer to have lower variance, even if it comes with a lower expected value of payoffs. Risk seeking is studied in many different contexts such as recreational sports, health-related behaviors or gambling preferences. A central question in behavioral sciences is: what factors determine the level of risk individuals are likely to engage in?

\section{The risk literature and its paradox}

The standard view in the literature argues that all kinds of risky behaviors, from investing in the stock market to wearing a seat belt, can be understood through risk preferences (Frey, Pedroni, Mata, Rieskamp, \& Hertwig, 2017; Lejuez et al., 2002; Rabin, 2013; Schonberg, Fox, \& Poldrack, 2011). According to this view, differences in the degree of risk aversion explain why some individuals are more likely to smoke, to buy an insurance policy, or to select a lottery with higher variance in economic games. In order to measure risk preferences, different tools have been developed: self-reported propensity measures (e.g. questionnaires asking "how risk-taking are you?"), incentivized behavioral measures (e.g. choosing between different lotteries), and frequency measures (e.g. reports on smoking frequency). These different tools are used interchangeably, as they are assumed to be measuring the same trait (Charness, Gneezy, \& Imas, 2013; Dohmen et al., 2011; Fouarge, Kriechel, \& Dohmen, 2014). Empirical 
findings, however, show that different measures of risk often do not correlate (Anderson \& Mellor, 2008; Deck, Lee, \& Reyes, 2014; Einav, Finkelstein, Pascu, \& Cullen, 2012; Menkhoff \& Sakha, 2017; Pedroni et al., 2017; Refaie \& Mishra, 2020; Vieider et al., 2015). Some studies find a link between risk preferences measured through tasks and real-life risky behaviors (Anderson \& Mellor, 2008), yet many studies fail to find such correlation (Armin, Becker, Dohmen, Huffman, \& Sunde, 2016; Creswell, Wright, Flory, Skrzynski, \& Manuck, 2019; Islam, Smyth, Tan, \& Wang, 2019). Although the lack of correlation between risk preferences and risky behaviors could be due to poor methods of measurement, these findings also suggest that risk preferences may not be the sole factor determining risky behaviors.

The 'behavioral syndrome literature', which classifies individuals into either a 'fast' risk-seeking group or a 'slow' risk-averse group, adopts a similar stance (Del Giudice, 2020; Griskevicius, Tybur, Delton, \& Robertson, 2011; Hill \& Chow, 2002; Hill, Ross, \& Low, 1997; Mata, Josef, \& Hertwig, 2016; Mathot \& Frankenhuis, 2018; Mishra, Barclay, \& Lalumière, 2014; Sear, 2020). According to this literature, the degree of risk aversion of individuals has been calibrated by natural selection to increase fitness in their particular environment, which explains inter-individual differences in risky behaviors. Being risk seeking is considered adaptive when living in deprived environments because individuals may be unlikely to achieve their goal with a safe strategy and may instead decide to maximize the probability of achieving their goal by adopting a riskier strategy (Mishra, 2014; Mishra, Barclay, \& Sparks, 2017; Mishra \& Lalumière, 2010). For example, studies of optimal foraging demonstrate that individuals whose average expected return on foraging is below the starvation threshold may adopt the riskier strategy to maximize the likelihood of survival (Caraco, Martindale, \& Whittam, 1980; Stephens D. W., 1981). The empirical literature in psychology and behavioral sciences indeed shows that deprived individuals tend to be more violent (Brezina, Agnew, Cullen, \& Wright, 2004; Shaw, 2005; Wells et al., 2019), take on riskier jobs (Leigh, 1986; Orrenius \& Zavodny, 2009; Sterling \& Weinkam, 1990), and engage in riskier health behaviours (Brennan, Henry, Nicholson, Kotowicz, \& Pasco, 
2009; Droomers, Schrijvers, Stronks, van de Mheen, \& Mackenbach, 1999; Everson, Maty, Lynch, \& Kaplan, 2002; Hanson \& Chen, 2007; Hersch \& Viscusi, 1998; Hiscock, Bauld, Amos, Fidler, \& Munafò, 2012; McLaren, 2007; Pampel, Krueger, \& Denney, 2010; Pill, Peters, \& Robling, 1995). Based on this evidence it is now widely accepted in the evolutionary psychology literature that risk seeking is part of the "behavioral constellation of deprivation" (Pepper \& Nettle, 2017).

However, economic studies offer evidence, on the contrary, for high risk aversion amongst deprived individuals. For example, when presented with different lotteries or with different investment decisions, deprived individuals are more likely to select the outcome with the smaller variance than wealthier individuals (Amir, Jordan, \& Rand, 2018; Refaie \& Mishra, 2020). Field studies offer similar findings when looking directly at people's financial decisions or willingness to take risks related to innovation or the adoption of new technology (Banerjee \& Duflo, 2011; Binswanger, 1981; Haushofer \& Fehr, 2014; Miyata, 2003; Mosley \& Verschoor, 2005; Tanaka, Camerer, \& Nguyen, 2010; ?). Table 1 outlines the type of risks taken, respectively, by high SES and low SES individuals. Low SES individuals appear to be both systematically more risk taking in certain domains and systematically less risk taking in others. How can we make sense of these seemingly contradictory findings?

\section{A missing factor in understanding risk taking}

Psychologists have attempted to explain these results by arguing that risk preferences may be domain specific (Figner \& Weber, 2011; Nicholson, Soane, Fenton-O'Creevy, \& Willman, 2005; Weber, Blais, \& Betz, 2002), or that risk preferences have a stable and an unstable component, similarly to other psychological traits (Frey et al., 2017; Highhouse, Nye, Zhang, \& Rada-Bayne, 2017). In this article, we offer a different explanation for the patterns of risk taking observed, namely that risk preferences are affected both by the variance and the temporality in the potential payoffs, as represented in Figure 1. Individuals with shorter time horizons will often engage in risky behaviours, seemingly displaying risk seeking preferences, when in fact they are 
only looking for short-term rewards. As a result, behaviors such as smoking or speeding do not reflect a preference for higher risk (i.e. higher variance in outcome), but a preference for sooner rather than later benefits (i.e. short term time preferences). In the next section, we develop a model which integrates the time horizon of individuals in their decisions to take risks.

\section{Steep temporal discounting leads to the neglect of hazards}

\section{Risk Preferences and marginal returns}

Risk preferences are defined as the individual preferences over the variance of outcomes. The degree of risk aversion, i.e. how willing an individual is to trade lower expected returns to obtain a smaller variance, depends on the marginal benefit of a particular outcome. An individual with diminishing marginal returns will be risk averse as each additional unit will lead to a smaller increase in fitness (the second glass of orange juice as compared to the first, for example). In this case, the individual will prefer the outcome with the least variance (one glass of orange juice for sure rather than two glasses of orange juice with a probability $p=\frac{1}{2}$ ). Most outcomes, from the quantity of food consumed to the traits of potential sexual partners, have diminishing marginal returns (Kenrick, Sundie, Nicastle, \& Stone, 2001). As such, we should expect individuals to have concave preferences. Individuals who are closer to saturation in a specific domain, will thus be less risk averse than individuals who enjoy large marginal benefits.

\section{Time preferences}

Risky choices that individuals face in ecological settings differ not only in their variance, but also in their temporality. For example, smoking may or may not lead to cancer, whereas non-smoking keeps one healthy with a high degree of certainty. These two alternatives therefore differ in the variance of their outcome, i.e. smoking is riskier than non-smoking. Smoking, however, also happens to have a delayed cost - a greater risk of cancer in 30 years - for an immediate benefit, while non smoking comes as a small cost 
today (refraining to smoke) for a positive outcome in the future (lower probability of cancer). The two alternatives therefore also differ in the temporality of their payoffs. One has a short term while the other has a long term benefit (and inversely for costs). Beyond this specific example, many decisions involving risks have an impact on an individual's capital (whether embodied capital, financial capital, reputation, relationships, etc.) and thus will affect an individual over a long period of time. As a result, the cognitive mechanisms that monitor the degree of risk we engage in must take into account both the benefits (costs) of each possible outcome and the time when these benefits (costs) will occur.

Let us start with an extreme case to illustrate our point. We assume that the life expectancy of an individual is 80 years. If that individual has a car accident and dies at 70 years old, then she will forego 10 years of expected life. If the same individual has a car accident and dies at 30 years old, she will forego 50 years of expected life. In evolutionary terms, the marginal cost of the car accident is proportional to the difference between the life expectancy and the age at death (10 years or 50 years respectively, see Figure 2), as each year of life lost is a year during which the individual will not be able to increase her inclusive fitness by producing more offspring or helping relatives (Clark, 1994; Wolf, van Doorn, Leimar, \& Weissing, 2007). Hence the cost of a fatal accident in evolutionary terms depends on the residual reproductive value of an individual. We implicitly follow this reasoning when we feel that a child's death is more tragic than the death of an elderly person.

A similar reasoning can be applied to all cases of risk-taking, even when they do not lead to such an extreme outcome as death. In evolutionary terms, the cost of an injury or, more generally, of a degradation of one's capital, always depends on one's time preferences. Let us consider the example of wearing a seat-belt. The cost of wearing a seat-belt during a given car ride is paid right now as a mild discomfort during the ride. The cost of not wearing a seat-belt, on the other hand, does not come to the individual on the ride in question. It will accrue to him on every day and at every instant of his future life, where he suffers from having an injured body. Conversely, the benefit of 
wearing a seat-belt accrues over time as an individual enjoys a healthy, non-injured body everyday following a potential accident. Individuals differ in their time horizons, some individuals will have immediate needs they must satisfy (short time horizon), while others can afford to invest in their future (long time horizon). Individuals who discount more steeply the future will care less about the long-term impact of the car accident on their health and thus take on more hazardous risk.

We apply this model to the case of wearing a seat-belt while driving (Figure 3). Imagine an individual is sitting in his car and has to decide whether to fasten his seat-belt (option $A$ ) or not (option $\bar{A}$ ). For simplicity, and without loss of generality, let's assume that if the individual fastens his seat-belt, he insures himself against all potential injuries in a crash. Wearing a seat-belt, however, comes with an immediate cost $c$ (e.g. because it takes time and causes discomfort during the ride). The total fitness payoff $F(A)$ of option $A$ is therefore $-c$ plus the temporal integration of the future productivity $\pi$ of the individual, which will have remained intact either way, as the individual is protected by his seat-belt. Let us assume that individuals have a discount rate $\delta \geq 0$, with higher values representing more present orientation. We can therefore write the expected payoff of option $A$ as:

$$
\begin{aligned}
f(A) & =-c+\int_{0}^{\infty} \pi e^{-\delta t} d t \\
& =-c+\frac{\pi}{\delta}
\end{aligned}
$$

If the individual decides to select option $\bar{A}$, on the other hand, he saves the cost $c$ of fastening his seat-belt, but he might be injured in the event of a crash. For simplicity, let us assume that if he crashes without his seat-belt on he will be injured with certainty. The cost of the injury will lie in a decreased productivity, $\pi-\Delta \pi$, every day of his life following the crash (e.g. because he cannot use one of his legs). Let us assume that the injury heals at a rate $\gamma$, and denote $p$ the probability of a crash occurring. The payoff for selecting option $\bar{A}$ is: 


$$
\begin{aligned}
f(\bar{A}) & =(1-p) \int_{0}^{\infty} \pi e^{-\delta t} d t+p \int_{0}^{\infty} \pi e^{-\delta t}-\Delta \pi e^{-(\delta+\gamma) t} d t \\
& =\frac{\pi}{\delta}-p \frac{\Delta \pi}{\delta+\gamma}
\end{aligned}
$$

The difference in payoffs from selecting option $A$ over option $\bar{A}$ is $f(A)-f(\bar{A})=-c+p \frac{\Delta \pi}{\delta+\gamma}$. Therefore it will be adaptive for individuals to select option $A$ if

$$
\delta+\gamma \leq \frac{p \Delta \pi}{c}
$$

From equation (1) we can see that for an individual to select option $A, p$ and $\Delta \pi$ must be large, meaning that either there is a high chance of having an accident or the corresponding injury will be very severe; or $c$ must be small, meaning that the inconvenience brought by wearing a seat-belt is small. In addition, individuals will also be more likely to wear a seat-belt if $\gamma$ and/or $\delta$ are small, that is recovery takes time and/or the individual has a low temporal discounting. Inter-individual differences in risk taking are therefore in part determined by inter-individual differences in temporal discounting. Irrespective of their preference over the variance of outcome per se, individuals who are more present-oriented tend to drive without a seat belt more often than future oriented individuals. Where $\gamma$ is very large, however, the effect of $\delta$ becomes negligible. That is to say, if the individual recovers from the injury the following day, her discount factor $\delta$ won't matter.

\section{Short time horizons lead to apparent preferences for risk}

So far, the standard approach in evolutionary psychology has failed to provide an explanation for the patterns of risk behaviors displayed across individuals. Our model suggests that differences in time horizon of individuals will lead to differences in the type of risks that individuals are likely to take. Individuals with short term horizons will discount the long-term costs of certain strategies and therefore be more likely to take risks which provide short term benefits for long terms costs, what we call 
hazardous behaviors. Conversely, individuals with short term horizon will discount the long-term benefits of certain strategies and therefore be less likely to take risks which provide a short term costs for a potential long term benefit, what we call venture behaviors. The same individuals may thus be willing to take risks in the form of hazards, but will not in the form of ventures.

A robust finding in both psychology and economics is that deprived individuals discount the future more than wealthier individuals do (Adams \& White, 2009; Bulley \& Pepper, 2017; de Wit, Flory, Acheson, McCloskey, \& Manuck, 2007; Green, Myerson, Lichtman, Rosen, \& Fry, 1996; Griskevicius et al., 2011; Lawrance, 1991; Robb, Simon, \& Wardle, 2009). In the evolutionary psychology literature, these findings are explained by collection risks and/or waiting costs. Individuals who have a high chance of dying because their environment is unstable and dangerous might not be able to collect the benefits of their investments (collection risk; Amir and Jordan (2017); Lee, DeBruine, and Jones (2018); Pepper and Nettle (2017)). Individuals living in deprived conditions might not afford to wait for a higher gain in the future because they need the benefits now (waiting costs; Fawcett, McNamara, and Houston (2012); Mell, Baumard, and André (2017)). As shown above, a steeper personal time discounting factor $\delta$ will result in choosing the riskier option when negative payoffs are spread in the future, which explains higher rates of smoking, risky sexual behavior, or risky jobs in low SES individuals. Conversely, individuals with shallow personal time discounting will value the riskier option more when positive payoffs are spread in the future, such as investing in risky financial assets or becoming an entrepreneur. This accounts for the pattern of risk taking observed across the socio-economic spectrum (Fig. 1).

\section{Discussion}

\section{Proximate versus ultimate mechanism for risk management}

The idea that an event that harms one's body, property, or social capital, does not have an outright cost but a cost spread over a long period of time is counter-intuitive. We rather tend to think of car accidents or other bad outcomes as one-off events with large 
immediate costs. This is the result of the difference between costs in the proximate sense - the negative valence of events as we perceive it, and costs in the ultimate sense the negative effect of these events on our fitness. The ultimate cost of a car accident is spread over time as it consists in a long-term drop in productivity. Our psychological mechanisms, however, evolved to value the total marginal effect of an event on our life-time reproductive success, to guide our behavior. At the proximate level, we thus tend to see accidents as having an immediate negative valence so that we avoid them. This product of our psychology should not be confused, however, with the time frame of fitness effects. Individuals differences in time horizon should also be reflected at a proximate level in difference in risk perception. Individuals with short time horizons should perceive hazardous behaviors as less risky than their more future oriented counterparts. Similarly, long term oriented individuals should perceive investing behavior as less risky than their present-oriented counterparts.

\section{Measuring risk preferences}

Our model suggests that risk preferences are affected both by the variance and the temporality of payoffs. As a results, risk preferences measures which take into account only one of these two factors are likely to be poor predictor of real-life risk taking. Our approach helps explain why behavioral tasks such as choosing between multiple price lists or the Balloon Analogue Risk Task (BART), are poor predictors of real-life risk taking (Frey et al., 2017; Islam et al., 2019; Mata, Frey, Richter, Schupp, \& Hertwig, 2018). These tasks measure only preferences for risk in terms of variance, but do not capture the temporal preferences of individuals. For example, the price selection task asks participants to select different lotteries where the payoffs are always occurring immediately (Andersen, Harrison, Lau, \& Rutström, 2006). Given there is no temporal trade-offs in this task, it does not reflect the preference for immediate benefits at the cost of potential long-term harm at play is hazardous behaviors. An individual may be risk averse (in terms of variance) and therefore prefer the safer lotteries in economic and psychology tasks, yet the same individual may also have a short time horizon and adopt 
hazardous behaviors. As a result, existing lab experiments measuring preferences over variance will often be poorly correlated to real-life risk taking.

Similarly, cognitive neurosciences have relied mostly on economic games such as lotteries or the Balloon Analogue Risk Task to identify a network of brain regions that respond to risk (Helfinstein et al., 2014; Li et al., 2020; Qi et al., 2015; Sela, Kilim, \& Lavidor, 2012; Suzuki, Jensen, Bossaerts, \& O’Doherty, 2016; Wei et al., 2016). Yet, given these tasks only measure preferences over variance, they do not predict real-life risk taking. In order to identify the separate underlying cognitive and neural mechanisms involved in real-life risk taking, researchers should distinguish between the variance path and the temporal path that both affect decision making. By varying the temporal horizon of a decision involving risk, neuroscientists can identify the role of temporal discounting separately from preferences over the variance of outcomes in risky behaviors. For example, participants should be asked to choose between lotteries with a large sure gain today and potential costs in the future, or a lottery with a smaller gain today but no cost in the future.

\section{Consequences for public policy}

Understanding risky behaviors such as smoking, speeding, or risky sexual practises as the result of a short-term strategy rather than a gamble, allows for better policies. Informing individuals about the long-term risk of smoking may not be effective if most smokers are present oriented. Instead, insisting on the immediate benefits of quitting may prove to be more effective. Similarly, reducing immediate costs to mitigate risk such as allowing for insurance payments to be spread in time or offering free preventive care, may be useful to encourage individuals to reduce the amount of hazards they expose themselves to. In addition, interventions that manipulate the time horizon of individuals may also be effective in reducing hazardous risks. Evidence show that Episodic Future Thinking, a method shown to increase the time horizon of individuals, is effective in reducing smoking in adults (Daniel, Said, Stanton, \& Epstein, 2015) and snacking in adolescents (Stein et al., 2016). 


\section{Limitations and future directions}

Although we question the assertion that deprived individuals have a systematic preference for outcomes with a high variance, there are some instances where this could be the case. Evolutionary models, such as the optimal foraging model presented by Stephens (Stephens D. W., 1981), demonstrate that in situations where an individual has a very high chance of falling below a critical threshold, it is optimal to adopt a risk-seeking behavior to maximize the probability of staying above the critical threshold. This principle is illustrated by the behavior of football players in the last minutes of a game (Gonzales, Mishra, \& Camp, 2017). Players in the loosing team might take more risks than usual, such as taking the goalie out of the end zone, to maximize their chance of scoring. In this type of desperate situation, only the high variance strategy has a chance to pay. This is not the case, however, in most real-life situations faced by low SES individuals. Someone who chooses not to brush their teeth, to postpone a medical appointment, or ride a motorcycle without a helmet is not gambling their life in the hope of a major breakthrough that would result from these behaviors. Rather, they are simply trading a long term cost (bad health) for an immediate benefit (not wasting time). The risk seeking strategy described by Stephens (Stephens D. W., 1981) comes into play only in rare situations where the choice is not repeated and survival is at play. Consequently, we argue that the behavioral constellation literature should consider removing risk-seeking and replacing it with short-termism as the leading cause for hazardous behaviors in deprived individuals.

From our model, a new typology of risk emerges: in addition to variance-oriented risks defined by the variance of outcomes, hazardous behaviors are defined by trading short term gains for potential long term losses (e.g. smoking, speeding, lying, etc.), and venture behaviors are defined by trading short term losses for potential long term gains (e.g. becoming an entrepreneur, adopting new technology, etc.). Although, in psychology, risk-seeking is often associated with negative outcomes such as the degradation of one's health, risk-seeking may also sometimes lead to positive outcomes. For example, entrepreneurs who are more risk seeking are often more successful (Macko 
\& Tyszka, 2009). There is often a trade-off between more conservative strategies with lower variance and lower expected returns and more exploratory strategies with higher variance and higher expected returns. These trade-offs are ubiquitous in one's life: should you have dinner in your favorite restaurant or try a new one? Should you mate with an existing partner or seek a new one? Although this exploration-exploitation dilemma has been often conceptualized in terms of a variance-expectation trade-off, we argue that the temporal dimension is equally important. Adopting an exploration strategy may delay the time when returns can accrue. Individuals who cannot afford to wait may therefore not be able to adopt such a strategy. As a result, these individuals may be stuck in a local optimum. We suggest that further studies should be conducted to test the impact of time horizon on exploration and innovation.

\section{Funding}

This study was supported by the EUR FrontCog grant ANR-17-EURE-0017. 


\section{References}

Adams, J., \& White, M. (2009). Time perspective in socioeconomic inequalities in smoking and body mass index. Health Psychology, 28(1), 83-90. Retrieved 2020-05-21, from http://doi.apa.org/getdoi.cfm?doi=10.1037/0278-6133.28.1.83 doi: 10.1037/0278-6133.28.1.83

Amir, D., \& Jordan, M. R. (2017). The behavioral constellation of deprivation may be best understood as risk management. Behavioral and Brain Sciences, 40, 66.

Amir, D., Jordan, M. R., \& Rand, D. G. (2018, November). An uncertainty management perspective on long-run impacts of adversity: The influence of childhood socioeconomic status on risk, time, and social preferences. Journal of Experimental Social Psychology, 79, 217-226. Retrieved 2020-05-18, from https://linkinghub.elsevier.com/retrieve/pii/S0022103118301082 doi: 10.1016/j.jesp.2018.07.014

Andersen, S., Harrison, G. W., Lau, M. I., \& Rutström, E. E. (2006, December). Elicitation using multiple price list formats. Experimental Economics, 9(4), 383-405. Retrieved 2020-05-28, from https://doi.org/10.1007/s10683-006-7055-6 doi: 10.1007/s10683-006-7055-6

Anderson, L. R., \& Mellor, J. M. (2008, September). Predicting health behaviors with an experimental measure of risk preference. Journal of Health Economics, 27(5), 1260-1274. Retrieved 2020-05-19, from https://linkinghub.elsevier.com/retrieve/pii/S0167629608000714 doi: 10.1016/j.jhealeco.2008.05.011

Armin, F., Becker, A., Dohmen, T. J., Huffman, D., \& Sunde, U. (2016). The Preference Survey Module: A Validated Instrument for Measuring Risk, Time, and Social Preferences. IZA Discussion Paper No. 9674. Retrieved 2020-04-15, from http://www.ssrn. com/abstract=2725874 doi: 10.2139/ssrn.2725874

Banerjee, A., \& Duflo, E. (2011). Poor economics : a radical rethinking of the way to 
fight global poverty.

Binswanger, H. P. (1981, December). Attitudes Toward Risk: Theoretical Implications of an Experiment in Rural India. The Economic Journal, $91(364), 867$. Retrieved 2020-02-03, from

https://academic.oup.com/ej/article/91/364/867-890/5219917 doi:

$10.2307 / 2232497$

Brennan, S. L., Henry, M. J., Nicholson, G. C., Kotowicz, M. A., \& Pasco, J. A. (2009, August). Socioeconomic status and risk factors for obesity and metabolic disorders in a population-based sample of adult females. Preventive Medicine, 49(2-3), 165-171. Retrieved 2020-02-07, from https://linkinghub.elsevier.com/retrieve/pii/S0091743509003247 doi: 10.1016/j.ypmed.2009.06.021

Brezina, T., Agnew, R., Cullen, F. T., \& Wright, J. P. (2004, October). The Code of the Street: A Quantitative Assessment of Elijah Anderson's Subculture of Violence Thesis and Its Contribution to Youth Violence Research. Youth Violence and Juvenile Justice, 2(4), 303-328. Retrieved 2020-02-07, from http://journals.sagepub.com/doi/10.1177/1541204004267780 doi: $10.1177 / 1541204004267780$

Bulley, A., \& Pepper, G. V. (2017, September). Cross-country relationships between life expectancy, intertemporal choice and age at first birth. Evolution and Human Behavior, 38(5), 652-658. Retrieved 2020-05-21, from https://linkinghub.elsevier.com/retrieve/pii/S1090513817300077 doi: 10.1016/j.evolhumbehav.2017.05.002

Caraco, T., Martindale, S., \& Whittam, T. S. (1980, August). An empirical demonstration of risk-sensitive foraging preferences. Animal Behaviour, 28(3), 820-830. Retrieved 2020-02-25, from https://linkinghub.elsevier.com/retrieve/pii/S0003347280801424 doi: 10.1016/S0003-3472(80)80142-4

Charness, G., Gneezy, U., \& Imas, A. (2013, March). Experimental methods: Eliciting 
risk preferences. Journal of Economic Behavior $\mathcal{6}$ Organization, 87, 43-51.

Retrieved 2020-05-26, from

https://linkinghub.elsevier.com/retrieve/pii/S016726811200282X doi:

10.1016/j.jebo.2012.12.023

Clark, C. W. (1994). Antipredator behavior and the asset-

protection principle. Behavioral Ecology, 5(2), 159-170. Retrieved 2020-09-14, from https://academic.oup.com/beheco/article-lookup/doi/10.1093/beheco/5.2.159 doi: $10.1093 /$ beheco/5.2.159

Creswell, K. G., Wright, A. G. C., Flory, J. D., Skrzynski, C. J., \& Manuck, S. B. (2019, July). Multidimensional assessment of impulsivity-related measures in relation to externalizing behaviors. Psychological Medicine, 49(10), 1678-1690. Retrieved 2020-03-28, from https://www . cambridge.org/core/product/identifier/S0033291718002295/type/journal doi: $10.1017 /$ S0033291718002295

Daniel, T. O., Said, M., Stanton, C. M., \& Epstein, L. H. (2015, August). Episodic future thinking reduces delay discounting and energy intake in children. Eating Behaviors, 18, 20-24. Retrieved 2020-05-21, from https://linkinghub.elsevier.com/retrieve/pii/S1471015315000380 doi: 10.1016/j.eatbeh.2015.03.006

Deck, C., Lee, J., \& Reyes, J. (2014, January). Investing versus gambling: experimental evidence of multi-domain risk attitudes. Applied Economics Letters, 21 (1), 19-23. Retrieved 2020-05-27, from http://www.tandfonline.com/doi/abs/10.1080/13504851.2013.835470 doi: $10.1080 / 13504851.2013 .835470$

Del Giudice, M. (2020). Rethinking the fast-slow continuum of individual differences. Evolution and Human Behavior, In press. Retrieved 2020-01-14, from https://osf.io/4uhz8 doi: 10.31234/osf.io/4uhz8

de Wit, H., Flory, J. D., Acheson, A., McCloskey, M., \& Manuck, S. B. (2007, January). IQ and nonplanning impulsivity are independently associated with delay 
discounting in middle-aged adults. Personality and Individual Differences, 42(1), 111-121. Retrieved 2020-05-21, from https://linkinghub.elsevier.com/retrieve/pii/S019188690600256X doi: 10.1016/j.paid.2006.06.026

Dohmen, T., Falk, A., Huffman, D., Sunde, U., Schupp, J., \& Wagner, G. G. (2011, June). Individual Risk Attitutes: Measurements, Determinants and Behavior Consequences. Journal of the European Economic Association, 9(3), 522-550. Retrieved 2020-05-27, from https://academic.oup.com/jeea/article-lookup/doi/10.1111/j.1542-4774.2011.01015. doi: $10.1111 / \mathrm{j} .1542-4774.2011 .01015 . \mathrm{x}$

Droomers, M., Schrijvers, C. T., Stronks, K., van de Mheen, D., \& Mackenbach, J. P. (1999, July). Educational Differences in Excessive Alcohol Consumption: The Role of Psychosocial and Material Stressors. Preventive Medicine, 29(1), 1-10. Retrieved 2020-02-07, from https://linkinghub.elsevier.com/retrieve/pii/S0091743599904966 doi: 10.1006/pmed.1999.0496

Einav, L., Finkelstein, A., Pascu, I., \& Cullen, M. R. (2012, October). How General Are Risk Preferences? Choices under Uncertainty in Different Domains. American Economic Review, 102(6), 2606-2638. Retrieved 2020-05-26, from http://pubs.aeaweb.org/doi/10.1257/aer.102.6.2606 doi: 10.1257/aer.102.6.2606

Everson, S. A., Maty, S. C., Lynch, J. W., \& Kaplan, G. A. (2002, October). Epidemiologic evidence for the relation between socioeconomic status and depression, obesity, and diabetes. Journal of Psychosomatic Research, 53(4), 891-895. Retrieved 2020-02-07, from https://linkinghub.elsevier.com/retrieve/pii/S0022399902003033 doi: 10.1016/S0022-3999(02)00303-3

Fawcett, T. W., McNamara, J. M., \& Houston, A. I. (2012, February). When is it adaptive to be patient? A general framework for evaluating delayed rewards. 
Behavioural Processes, 89(2), 128-136. Retrieved 2020-02-28, from https://linkinghub.elsevier.com/retrieve/pii/S0376635711001689 doi: 10.1016/j.beproc.2011.08.015

Figner, B., \& Weber, E. U. (2011, August). Who Takes Risks When and Why?: Determinants of Risk Taking. Current Directions in Psychological Science, 20(4), 211-216. Retrieved 2020-05-28, from https://doi.org/10.1177/0963721411415790 (Publisher: SAGE Publications Inc) doi: 10.1177/0963721411415790

Fouarge, D., Kriechel, B., \& Dohmen, T. (2014, October). Occupational sorting of school graduates: The role of economic preferences. Journal of Economic Behavior $\mathscr{E}$ Organization, 106, 335-351. Retrieved 2020-05-27, from https://linkinghub.elsevier.com/retrieve/pii/S016726811400208X doi: 10.1016/j.jebo.2014.07.007

Frey, R., Pedroni, A., Mata, R., Rieskamp, J., \& Hertwig, R. (2017, October). Risk preference shares the psychometric structure of major psychological traits. Science Advances, 3(10), e1701381. Retrieved 2020-03-03, from https://advances.sciencemag.org/lookup/doi/10.1126/sciadv.1701381 doi: $10.1126 /$ sciadv.1701381

Gonzales, J., Mishra, S., \& Camp, R. D. (2017). For the Win: Risk-Sensitive Decision-Making in Teams. Journal of Behavioral Decision Making, 30(2), 462-472. Retrieved 2020-05-28, from https://onlinelibrary.wiley.com/doi/abs/10.1002/bdm.1965 (_eprint: https://onlinelibrary.wiley.com/doi/pdf/10.1002/bdm.1965) doi: 10.1002/bdm. 1965

Green, L., Myerson, J., Lichtman, D., Rosen, S., \& Fry, A. (1996). Temporal Discounting in Choice Between Delayed Rewards: The Role of Age and Income. Psychology and Aging, 11(1), 79-84.

Griskevicius, V., Tybur, J. M., Delton, A. W., \& Robertson, T. E. (2011). The influence of mortality and socioeconomic status on risk and delayed rewards: A 
life history theory approach. Journal of Personality and Social Psychology, $100(6)$, 1015-1026. Retrieved 2020-02-06, from http://doi.apa.org/getdoi.cfm?doi=10.1037/a0022403 doi: $10.1037 / \mathrm{a} 0022403$

Hanson, M. D., \& Chen, E. (2007, June). Socioeconomic Status and Health Behaviors in Adolescence: A Review of the Literature. Journal of Behavioral Medicine, 30(3), 263-285. Retrieved 2020-02-06, from http://link.springer.com/10.1007/s10865-007-9098-3 doi: $10.1007 / \mathrm{s} 10865-007-9098-3$

Haushofer, J., \& Fehr, E. (2014, May). On the psychology of poverty. Science, 344(6186), 862-867. Retrieved 2020-02-07, from https://www.sciencemag.org/lookup/doi/10.1126/science.1232491 doi: $10.1126 /$ science. 1232491

Helfinstein, S. M., Schonberg, T., Congdon, E., Karlsgodt, K. H., Mumford, J. A., Sabb, F. W., ... Poldrack, R. A. (2014, February). Predicting risky choices from brain activity patterns. Proceedings of the National Academy of Sciences, 111(7), 2470-2475. Retrieved 2020-05-28, from http://www.pnas.org/cgi/doi/10.1073/pnas.1321728111 doi: $10.1073 /$ pnas. 1321728111

Hersch, J., \& Viscusi, W. K. (1998, July). Smoking and other Risky Behaviors. Journal of Drug Issues, 28(3), 645-661. Retrieved 2020-02-06, from http://journals.sagepub.com/doi/10.1177/002204269802800305 doi: $10.1177 / 002204269802800305$

Highhouse, S., Nye, C., Zhang, D., \& Rada-Bayne, T. B. (2017). Structure of the Dospert: Is there evidence for a general risk factor? Journal of Behavioral Decision Making, 30(2), 400-406.

Hill, E. M., \& Chow, K. (2002). Life-history theory and risky drinking. , 13.

Hill, E. M., Ross, L. T., \& Low, B. S. (1997, December). The role of future unpredictability in human risk-taking. Human Nature, 8(4), 287-325. Retrieved 
2020-02-07, from http://link.springer.com/10.1007/BF02913037 doi: 10.1007/BF02913037

Hiscock, R., Bauld, L., Amos, A., Fidler, J. A., \& Munafò, M. (2012, February). Socioeconomic status and smoking: a review: Hiscock et al. Annals of the New York Academy of Sciences, 1248(1), 107-123. Retrieved 2020-02-06, from http://doi.wiley.com/10.1111/j.1749-6632.2011.06202.x doi: 10.1111/j.1749-6632.2011.06202.x

Islam, A., Smyth, R., Tan, H. A., \& Wang, L. C. (2019, October). Survey measures versus incentivized measures of risk preferences: Evidence from sex workers' risky sexual transactions. Social Science \&3 Medicine, 238, 112497. Retrieved 2020-05-19, from https://linkinghub.elsevier.com/retrieve/pii/S0277953619304903 doi: 10.1016/j.socscimed.2019.112497

Kenrick, D. T., Sundie, J. M., Nicastle, L. D., \& Stone, G. O. (2001). Can One Ever Be Too Wealthy or Too Chaste? Searching for Nonlinearities in Mate Judgment. Journal of Personality and Social Psychology, 80(3), 462-471.

Lawrance, E. C. (1991). Poverty and the rate of time preference: Evidence from panel data. Journal of Political Economy, 99(1), 54-77.

Lee, A. J., DeBruine, L. M., \& Jones, B. C. (2018, June). Individual-specific mortality is associated with how individuals evaluate future discounting decisions.

Proceedings of the Royal Society B: Biological Sciences, 285(1880), 20180304.

Retrieved 2020-05-28, from https://royalsocietypublishing.org/doi/full/10.1098/rspb.2018.0304 (Publisher: Royal Society) doi: 10.1098/rspb.2018.0304

Leigh, J. (1986, January). Who chooses risky jobs? Social Science \& Medicine, 23(1), 57-64. Retrieved 2020-02-07, from https://linkinghub.elsevier.com/retrieve/pii/0277953686903242 doi: 10.1016/0277-9536(86)90324-2

Lejuez, C. W., Read, J. P., Kahler, C. W., Richards, J. B., Ramsey, S. E., Stuart, G. L., 
... Brown, R. A. (2002). Evaluation of a behavioral measure of risk taking: The Balloon Analogue Risk Task (BART). Journal of Experimental Psychology: Applied, 8(2), 75-84. Retrieved 2020-05-26, from http://doi.apa.org/getdoi.cfm?doi=10.1037/1076-898X.8.2.75 doi: 10.1037/1076-898X.8.2.75

Li, X., Pan, Y., Fang, Z., Lei, H., Zhang, X., Shi, H., .. Rao, H. (2020, April). Test-retest reliability of brain responses to risk-taking during the balloon analogue risk task. NeuroImage, 209, 116495. Retrieved 2020-05-28, from http://www.sciencedirect.com/science/article/pii/S1053811919310869 doi: 10.1016/j.neuroimage.2019.116495

Macko, A., \& Tyszka, T. (2009, July). Entrepreneurship and Risk Taking. Applied Psychology, 58(3), 469-487. Retrieved 2020-09-17, from http://doi.wiley.com/10.1111/j.1464-0597.2009.00402.x doi: 10.1111/j.1464-0597.2009.00402.x

Mata, R., Frey, R., Richter, D., Schupp, J., \& Hertwig, R. (2018, May). Risk Preference: A View from Psychology. Journal of Economic Perspectives, 32(2), 155-172. Retrieved 2020-05-28, from https://pubs.aeaweb.org/doi/10.1257/jep.32.2.155 doi: $10.1257 /$ jep.32.2.155

Mata, R., Josef, A. K., \& Hertwig, R. (2016, February). Propensity for Risk Taking Across the Life Span and Around the Globe. Psychological Science, 27(2), 231-243. Retrieved 2020-02-07, from http://journals.sagepub.com/doi/10.1177/0956797615617811 doi: $10.1177 / 0956797615617811$

Mathot, K. J., \& Frankenhuis, W. E. (2018, March). Models of pace-of-life syndromes (POLS): a systematic review. Behavioral Ecology and Sociobiology, 72(3), 41. Retrieved 2020-02-28, from http://link.springer.com/10.1007/s00265-018-2459-9 doi: $10.1007 / \mathrm{s} 00265-018-2459-9$ 
McLaren, L. (2007, May). Socioeconomic Status and Obesity. Epidemiologic Reviews, 29(1), 29-48. Retrieved 2020-02-07, from https://academic.oup.com/epirev/article-lookup/doi/10.1093/epirev/mxm001 doi: 10.1093/epirev/mxm001

Mell, H., Baumard, N., \& André, J.-B. (2017). Both collection risk and waiting costs give rise to the behavioral constellation of deprivation. Behavioral and Brain Sciences, 40, e314. Retrieved 2020-02-25, from https://www . cambridge.org/core/product/identifier/S0140525X1600234X/type/journal doi: $10.1017 / \mathrm{s} 0140525 \times 17001030$

Menkhoff, L., \& Sakha, S. (2017, April). Estimating risky behavior with multiple-item risk measures. Journal of Economic Psychology, 59, 59-86. Retrieved 2020-05-26, from https://linkinghub.elsevier.com/retrieve/pii/S0167487016304196 doi: $10.1016 /$ j.joep.2017.02.005

Mishra, S. (2014, August). Decision-Making Under Risk: Integrating Perspectives From Biology, Economics, and Psychology. Personality and Social Psychology Review, 18(3), 280-307. Retrieved 2020-05-28, from http://journals. sagepub.com/doi/10.1177/1088868314530517 doi: $10.1177 / 1088868314530517$

Mishra, S., Barclay, P., \& Lalumière, M. L. (2014, March). Competitive disadvantage facilitates risk taking. Evolution and Human Behavior, 35 (2), 126-132. Retrieved 2020-02-19, from https://linkinghub.elsevier.com/retrieve/pii/S1090513813001360 doi: 10.1016/j.evolhumbehav.2013.11.006

Mishra, S., Barclay, P., \& Sparks, A. (2017, May). The Relative State Model: Integrating Need-Based and Ability-Based Pathways to Risk-Taking. Personality and Social Psychology Review, 21(2), 176-198. Retrieved 2020-05-28, from http://journals.sagepub.com/doi/10.1177/1088868316644094 doi: $10.1177 / 1088868316644094$

Mishra, S., \& Lalumière, M. L. (2010, July). You can’t always get what you want: The 
motivational effect of need on risk-sensitive decision-making. Journal of Experimental Social Psychology, 46(4), 605-611. Retrieved 2020-05-28, from http://www.sciencedirect.com/science/article/pii/S0022103109003151 doi: 10.1016/j.jesp.2009.12.009

Miyata, S. (2003, April). Household's risk attitudes in Indonesian villages. Applied Economics, 35(5), 573-583. Retrieved 2020-02-07, from http://www.tandfonline.com/doi/abs/10.1080/0003684022000020823 doi: $10.1080 / 0003684022000020823$

Mosley, P., \& Verschoor, A. (2005, March). Risk Attitudes and the 'Vicious Circle of Poverty'. The European Journal of Development Research, 17(1), 59-88.

Retrieved 2020-02-06, from http://link.springer.com/10.1080/09578810500066548 doi: $10.1080 / 09578810500066548$

Nicholson, N., Soane, E., Fenton-O'Creevy, M., \& Willman, P. (2005, March). Personality and domain-specific risk taking. Journal of Risk Research, 8(2), 157-176. Retrieved 2020-05-26, from https://www.tandfonline.com/doi/full/10.1080/1366987032000123856 doi: $10.1080 / 1366987032000123856$

Orrenius, P. M., \& Zavodny, M. (2009). Do immigrants work in riskier jobs? Demography, 46(3), 535-551.

Pampel, F. C., Krueger, P. M., \& Denney, J. T. (2010). Socioeconomic Disparities in Health Behaviors. Annual Review of Sociology, 36(1), 349-370. Retrieved 2020-02-06, from https://doi.org/10.1146/annurev.soc.012809.102529 doi: 10.1146/annurev.soc.012809.102529

Pedroni, A., Frey, R., Bruhin, A., Dutilh, G., Hertwig, R., \& Rieskamp, J. (2017, November). The risk elicitation puzzle. Nature Human Behaviour, 1(11), 803-809. Retrieved 2020-03-26, from http://www . nature.com/articles/s41562-017-0219-x doi: $10.1038 /$ s41562-017-0219-x 
Pepper, G. V., \& Nettle, D. (2017). The behavioural constellation of deprivation: Causes and consequences. Behavioral and Brain Sciences, 40. Retrieved 2020-02-07, from https://www.cambridge.org/core/product/identifier/S0140525X1600234X/type/journal doi: 10.1017/S0140525X1600234X

Pill, R., Peters, T. J., \& Robling, M. R. (1995, February). Social class and preventive health behaviour: a British example. Journal of Epidemiology $\& 5$ Community Health, 49(1), 28-32. Retrieved 2020-02-07, from http://jech.bmj.com/cgi/doi/10.1136/jech.49.1.28 doi: 10.1136/jech.49.1.28

Qi, X., Du, X., Yang, Y., Du, G., Gao, P., Zhang, Y., ... Zhang, Q. (2015). Decreased modulation by the risk level on the brain activation during decision making in adolescents with internet gaming disorder. Frontiers in Behavioral Neuroscience, 9. Retrieved 2020-05-28, from https://www.frontiersin.org/articles/10.3389/fnbeh.2015.00296/full (Publisher: Frontiers) doi: 10.3389/fnbeh.2015.00296

Rabin, M. (2013). Risk aversion and expected-utility theory: A calibration theorem. Handbook of the Fundamentals of Financial Decision Making, 12.

Refaie, N., \& Mishra, S. (2020, February). Embodied Capital and Risk-Related Traits, Attitudes, Behaviors, and Outcomes: An Exploratory Examination of Attractiveness, Cognitive Ability, and Physical Ability. Social Psychological and Personality Science, 194855061988203. Retrieved 2020-02-19, from http://journals.sagepub.com/doi/10.1177/1948550619882036 doi: $10.1177 / 1948550619882036$

Robb, K. A., Simon, A. E., \& Wardle, J. (2009, December). Socioeconomic Disparities in Optimism and Pessimism. International Journal of Behavioral Medicine, 16(4), 331-338. Retrieved 2020-05-21, from http://link. springer.com/10.1007/s12529-008-9018-0 doi: $10.1007 / \mathrm{s} 12529-008-9018-0$ 
Schonberg, T., Fox, C. R., \& Poldrack, R. A. (2011, January). Mind the gap: bridging economic and naturalistic risk-taking with cognitive neuroscience. Trends in Cognitive Sciences, 15(1), 11-19. Retrieved 2020-04-29, from https://linkinghub.elsevier.com/retrieve/pii/S1364661310002366 doi: $10.1016 /$ j.tics.2010.10.002

Sear, R. (2020, February). Do human 'life history strategies' exist? (preprint). Open Science Framework. Retrieved 2020-02-28, from https://osf.io/hjezb doi: 10.31219/osf.io/hjezb

Sela, T., Kilim, A., \& Lavidor, M. (2012). Transcranial Alternating Current Stimulation Increases Risk-Taking Behavior in the Balloon Analog Risk Task. Frontiers in Neuroscience, 6. Retrieved 2020-05-28, from https://www.frontiersin.org/articles/10.3389/fnins.2012.00022/full (Publisher: Frontiers) doi: 10.3389/fnins.2012.00022

Shaw, M. (2005, March). Increasing inequalities in risk of murder in Britain: trends in the demographic and spatial distribution of murder, 1981 - 2000. Health $\&$ Place, 11(1), 45-54. Retrieved 2020-02-07, from https://linkinghub.elsevier.com/retrieve/pii/S135382920400005X doi: 10.1016/j.healthplace.2004.01.003

Stein, J. S., Wilson, A. G., Koffarnus, M. N., Daniel, T. O., Epstein, L. H., \& Bickel, W. K. (2016, October). Unstuck in time: episodic future thinking reduces delay discounting and cigarette smoking. Psychopharmacology, 233(21-22), 3771-3778. Retrieved 2020-05-21, from http://link.springer.com/10.1007/s00213-016-4410-y doi: 10.1007/s00213-016-4410-y

Stephens D. W., A. B. (1981, May). The Logic of Risk-Sensitive Foraging Preferences. Animal Behaviour, 29(2), 628-629. Retrieved 2020-01-29, from https://linkinghub.elsevier.com/retrieve/pii/S0003347281801297 doi: 10.1016/S0003-3472(81)80129-7

Sterling, T., \& Weinkam, J. (1990, January). The confounding of occupation and 
smoking and its consequences. Social Science 85 Medicine, 30(4), 457-467.

Retrieved 2020-02-07, from

https://linkinghub.elsevier.com/retrieve/pii/027795369090348V doi: 10.1016/0277-9536(90)90348-V

Suzuki, S., Jensen, E. L. S., Bossaerts, P., \& O’Doherty, J. P. (2016, April). Behavioral contagion during learning about another agent's risk-preferences acts on the neural representation of decision-risk. Proceedings of the National Academy of Sciences, 113(14), 3755-3760. Retrieved 2020-05-26, from http://www.pnas.org/lookup/doi/10.1073/pnas.1600092113 doi: $10.1073 /$ pnas. 1600092113

Tanaka, T., Camerer, C. F., \& Nguyen, Q. (2010, March). Risk and Time Preferences: Linking Experimental and Household Survey Data from Vietnam. American Economic Review, 100(1), 557-571. Retrieved 2020-02-03, from http://pubs.aeaweb.org/doi/10.1257/aer.100.1.557 doi: $10.1257 /$ aer.100.1.557

Vieider, F. M., Lefebvre, M., Bouchouicha, R., Chmura, T., Hakimov, R., Krawczyk, M., \& Martinsson, P. (2015, June). Common Components of Risk and Uncertainty Attitudes Across Contexts and Domains: Evidence from 30 Countries. Journal of the European Economic Association, 13(3), 421-452. Retrieved 2020-05-27, from https://academic.oup.com/jeea/article/13/3/421/2319769 (Publisher: Oxford Academic) doi: 10.1111/jeea.12102

Weber, E. U., Blais, A.-R., \& Betz, N. E. (2002, October). A domain-specific risk-attitude scale: measuring risk perceptions and risk behaviors. Journal of Behavioral Decision Making, 15(4), 263-290. Retrieved 2020-04-15, from http://doi.wiley.com/10.1002/bdm.414 doi: 10.1002/bdm.414

Wei, Z., Yang, N., Liu, Y., Yang, L., Wang, Y., Han, L., .. Zhang, X. (2016, February). Resting-state functional connectivity between the dorsal anterior cingulate cortex and thalamus is associated with risky decision-making in nicotine addicts. Scientific Reports, 6(1), 21778. Retrieved 2020-05-28, from 
https://www.nature.com/articles/srep21778 (Number: 1 Publisher: Nature Publishing Group) doi: 10.1038/srep21778

Wells, J. C. K., Cole, T. J., Cortina-Borja, M., Sear, R., Leon, D. A., Marphatia, A. A., .. Menezes, A. M. B. (2019, July). Low Maternal Capital Predicts Life History Trade-Offs in Daughters: Why Adverse Outcomes Cluster in Individuals.

Frontiers in Public Health, 7, 206. Retrieved 2020-02-28, from

https://www.frontiersin.org/article/10.3389/fpubh.2019.00206/full doi: 10.3389/fpubh.2019.00206

Wolf, M., van Doorn, G. S., Leimar, O., \& Weissing, F. J. (2007, May). Life-history trade-offs favour the evolution of animal personalities. Nature, 447(7144), 581-584. Retrieved 2020-09-14, from http://www.nature.com/articles/nature05835 doi: 10.1038/nature05835 
Table 1

Patterns of risky behavior by socioeconomic status

\begin{tabular}{|c|c|c|c|}
\hline \multicolumn{4}{|c|}{ Risky Behaviors } \\
\hline Type of risky behavior & High SES & Low SES & Reference \\
\hline Risky financial investments & High & Low & $\begin{array}{l}\text { Haushofer \& Fehr, 2014; Miy- } \\
\text { ata, 2003; Mosley \& Ver- } \\
\text { schoor, } 2005\end{array}$ \\
\hline $\begin{array}{l}\text { Cigarette and alcohol con- } \\
\text { sumption }\end{array}$ & Low & High & $\begin{array}{l}\text { Droomers, Schrijvers, } \\
\text { Stronks, van de Mheen, } \\
\text { \& Mackenbach, 1999; Ever- } \\
\text { son, Maty, Lynch, \& Kaplan, } \\
\text { 2002; Hanson \& Chen, 2007; } \\
\text { Hersch \& Viscusi, 1998; His- } \\
\text { cock, Bauld, Amos, Fidler, } \\
\text { \& Munafò, 2012; Pampel, } \\
\text { Krueger, \& Denney, 2010 }\end{array}$ \\
\hline Violent behavior & Low & High & $\begin{array}{l}\text { Brezina, Agnew, Cullen, \& } \\
\text { Wright, 2004; Shaw, 2005; } \\
\text { Wells et al., } 2019\end{array}$ \\
\hline Entrepreneurship & High & Low & $\begin{array}{l}\text { Banerjee \& Duflo, 2011; } \\
\text { Nielsen, Keil, \& Zeller, } 2013\end{array}$ \\
\hline Dangerous Jobs & Low & High & $\begin{array}{l}\text { Leigh, 1986; Orrenius \& } \\
\text { Zavodny, 2009; Sterling \& } \\
\text { Weinkam, } 1990\end{array}$ \\
\hline
\end{tabular}




\section{Single Factor View: Only Risk Preferences Explain Risky Behaviors}

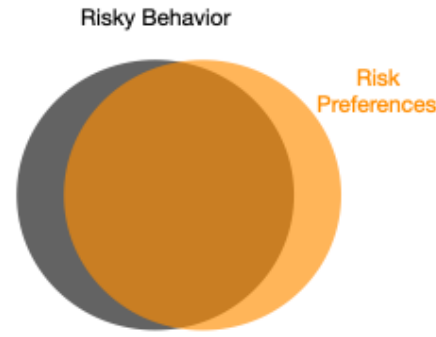

\begin{tabular}{|c|c|}
\hline \multicolumn{2}{|c|}{ Risk Preferences } \\
\hline High Variance & Low Variance \\
\hdashline $\begin{array}{c}\text { E.g. Earn } 25 € \text { with } \\
\text { probability } p=0.5\end{array}$ & $\begin{array}{c}\text { E.g. Earn } 10 € \text { for } \\
\text { sure }\end{array}$ \\
\hline & \\
\hline
\end{tabular}

Composite View: Both Risk Preferences and Time Preferences Explain Risky Behaviors

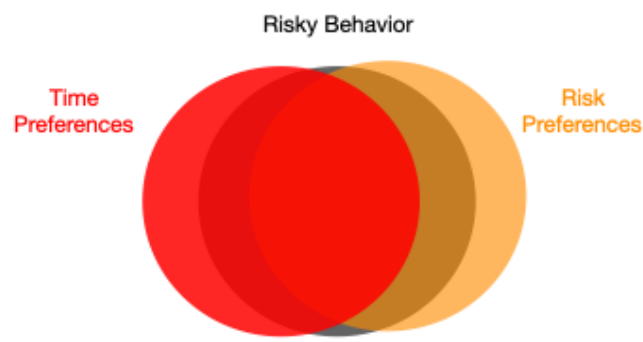

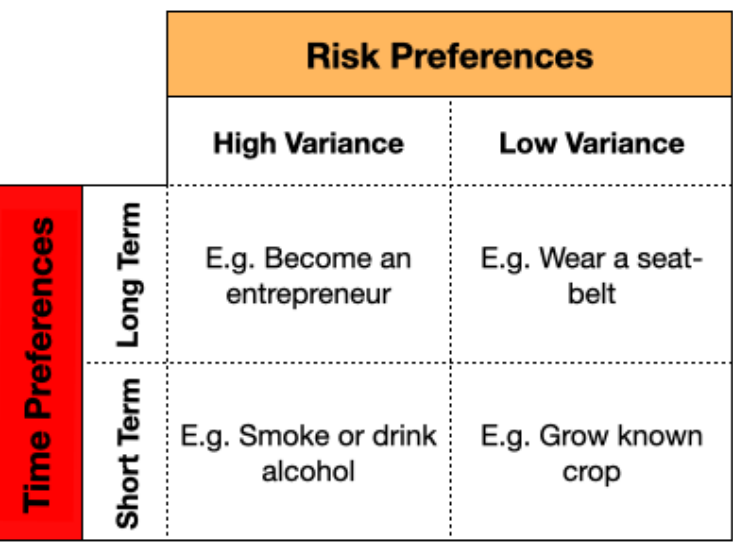

Figure 1. Two views of the determinants of risk taking. The standard approach only studies the impact of variance on risk taking behavior. The approach we propose takes into account both the variance in payoffs and the temporality of payoffs. As a result, two types of risk emerge: present-oriented risks and future oriented risks. 


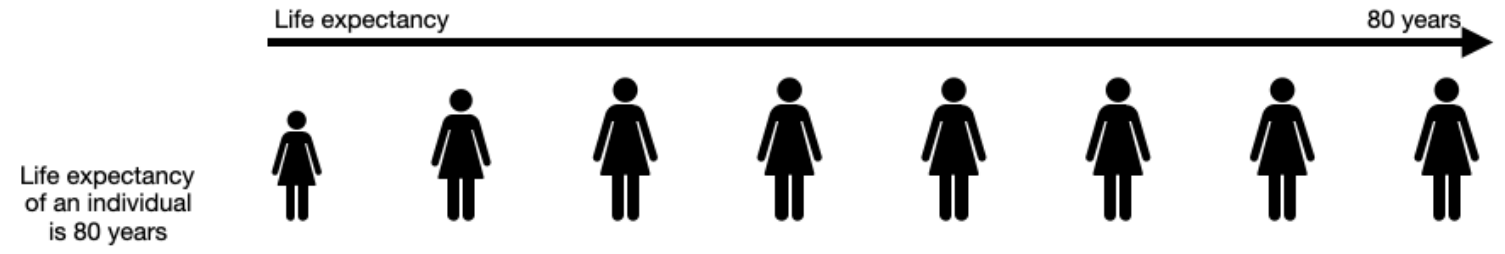

The cost of death in terms of fitness is proportional to the difference between life expectancy and age at death

Death occurs at 70 years old, 10 years of expected life foregone
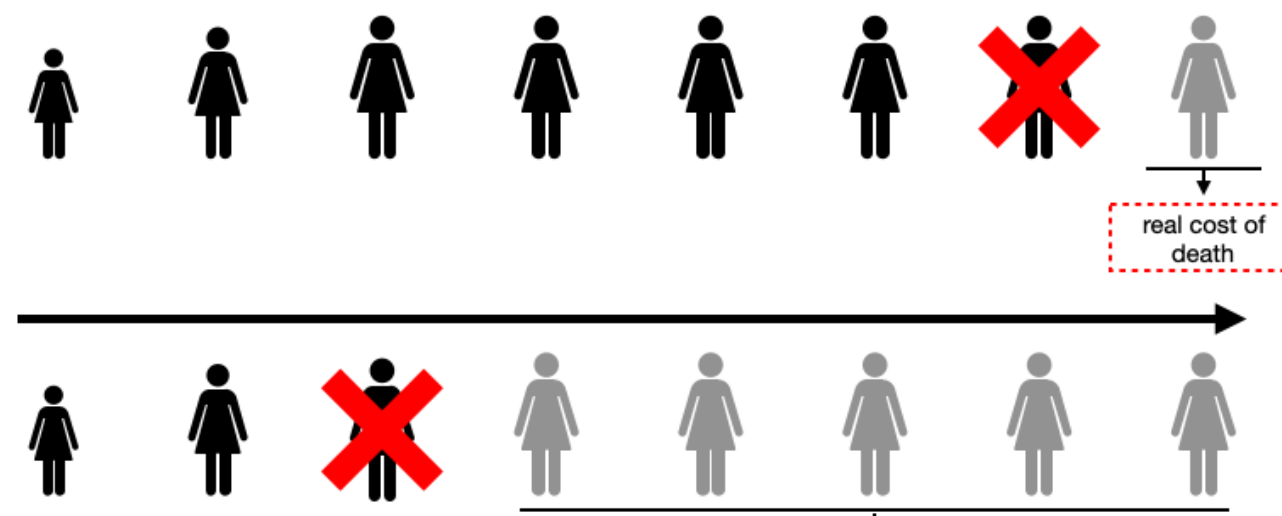

real cost of death

Death occurs at 30 years old, 50 years of expected life foregone

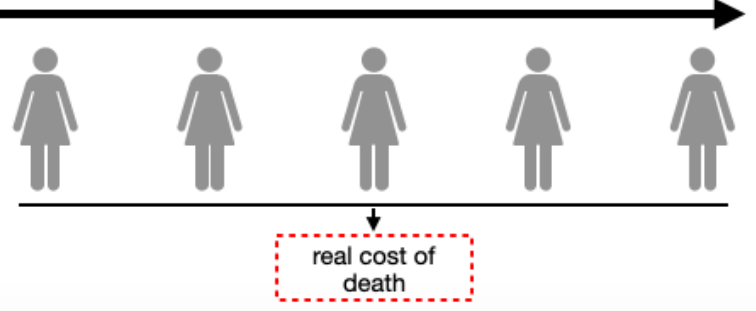

Figure 2. The marginal cost of death depends on the future reproductive value of the individual
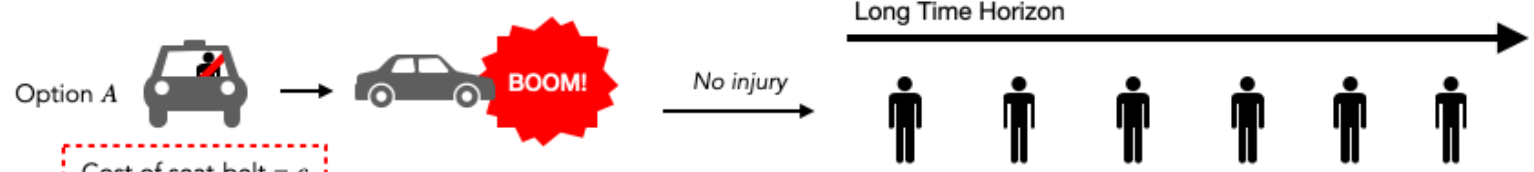

Cost of seat-belt $=c$
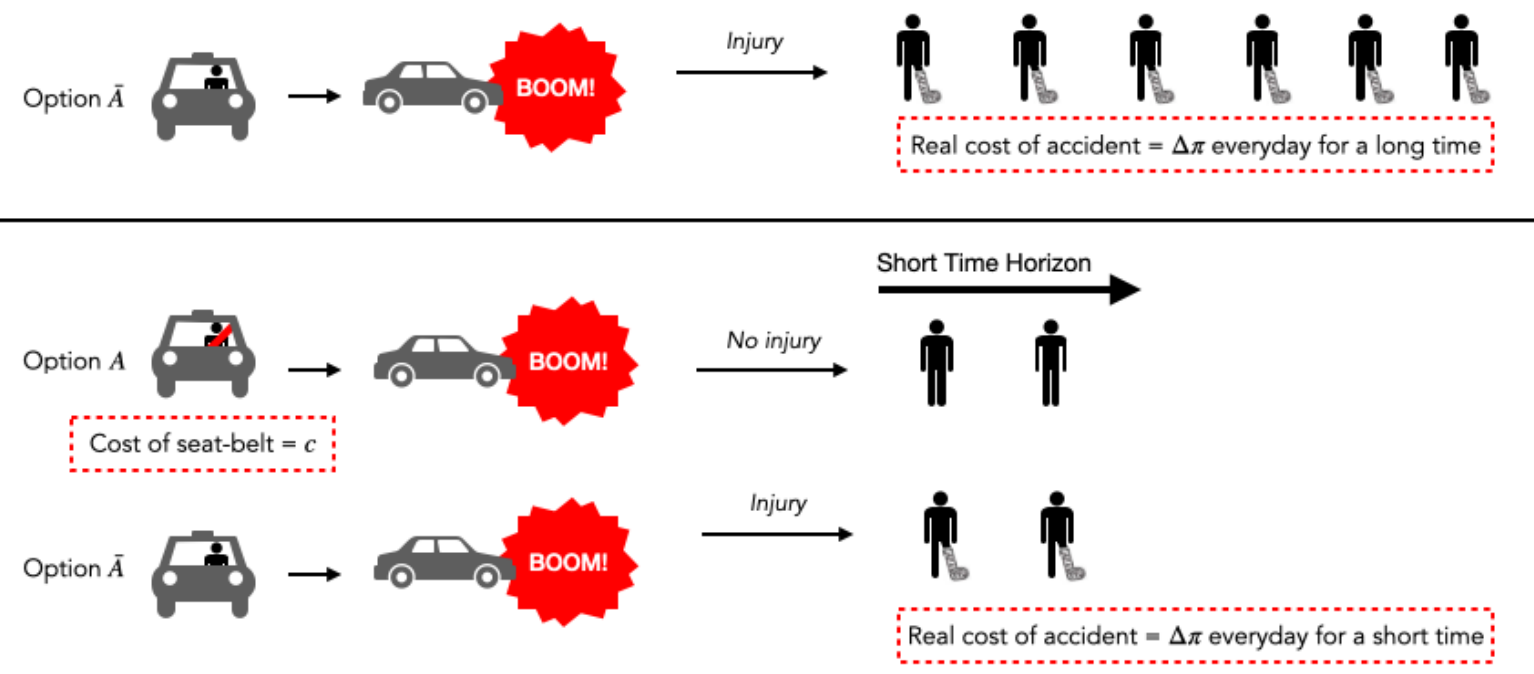

Figure 3. The marginal cost of injury depends on the time horizon of an individual. 